Supporting Information for:

\title{
Passivation of Nickel Vacancy Defects in Nickel Oxide Solar Cells by Targeted Atomic Deposition of Boron
}

Cory J. Flynn ${ }^{1}$, Shannon M. McCullough ${ }^{1}$, Lesheng Li ${ }^{1}$, Carrie L. Donley ${ }^{2}$, Yosuke Kanai ${ }^{1}$, and James F. Cahoon ${ }^{1 *}$

${ }^{1}$ Department of Chemistry, University of North Carolina at Chapel Hill, Chapel Hill, NC 275993290, USA. ${ }^{2}$ Chapel Hill Analytical and Nanofabrication Laboratory (CHANL), Department of Applied Physical Sciences, University of North Carolina at Chapel Hill, Chapel Hill, NC 275993216, USA

*email: J.F.C. (jfcahoon@unc.edu)

This document includes:

Figures S1-S7

Table S1 

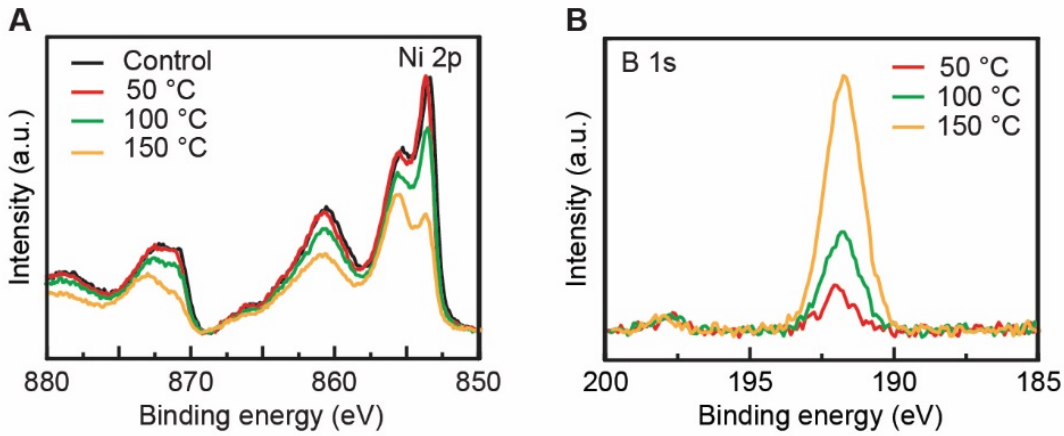

Figure S1. Unscaled background-corrected XPS spectra. (A) Ni 2p and (B) B 1s spectra of NiO without treatment (black traces) and with a TAD of B for $1000 \mathrm{~s}$ at $50{ }^{\circ} \mathrm{C}$ (red traces), $100{ }^{\circ} \mathrm{C}$ (green traces), and $150{ }^{\circ} \mathrm{C}$ (yellow traces). The intensity of the $\mathrm{Ni} 2 \mathrm{p}$ spectra is greatly diminished after treatment at $150{ }^{\circ} \mathrm{C}$ due to the significant B deposition. For Figure 1B, the experimental intensities of the background corrected B 1s spectra were normalized by dividing by the integration of the Ni $2 p$ spectra for each sample. 


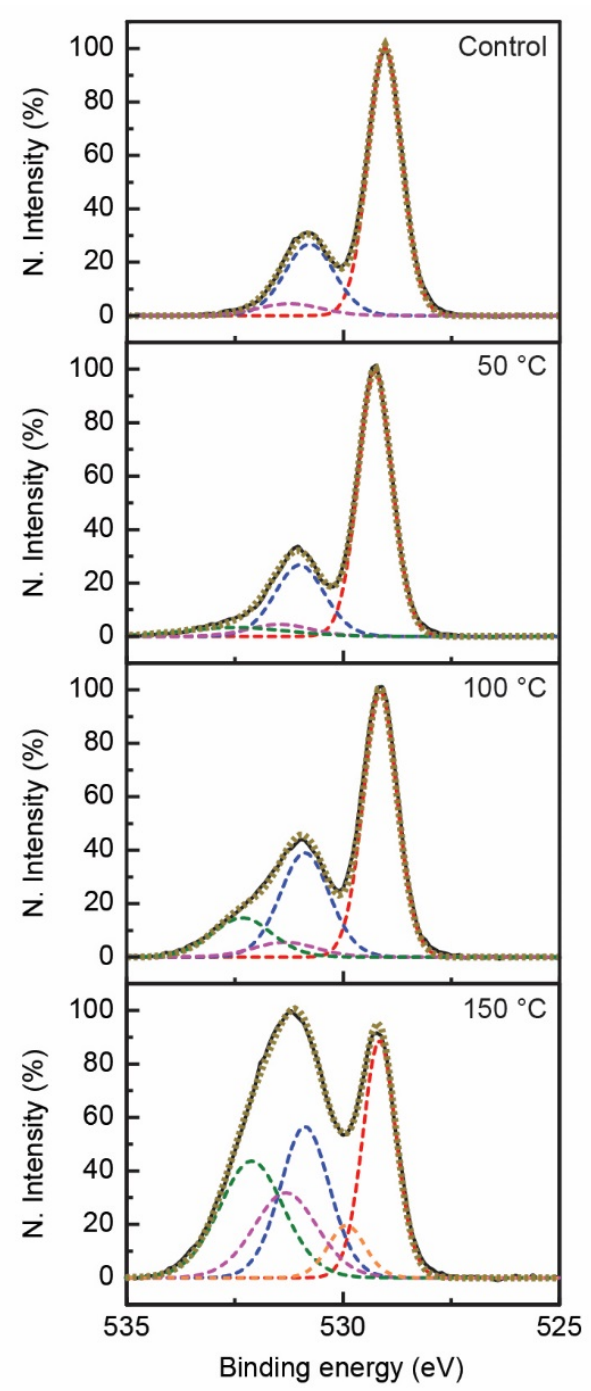

Figure S2. Analytical fitting of O 1s XPS spectra. XPS spectra of NiO without treatment (upper) and with treatment for $1000 \mathrm{~s}$ at increasing deposition temperatures of $50{ }^{\circ} \mathrm{C}$ (upper middle), $100{ }^{\circ} \mathrm{C}$ (lower middle), and $150{ }^{\circ} \mathrm{C}$ (lower). Dashed lines represent the fitted Voigt functions or the summation of the fit (gold dashed line). All spectra are normalized to their highest peak intensity. The three peaks used to fit the control $\mathrm{NiO}$ data were used to fit the B-treated samples by fixing the relative peak positions and peak widths but allowing the peak height to vary. For the $50^{\circ} \mathrm{C}$ and $100{ }^{\circ} \mathrm{C}$ data, one additional peak, relative to the control sample, was required at high binding energies to accurately fit the data. For the $150^{\circ} \mathrm{C}$ data, two additional peaks, relative to the control sample, were required to achieve a satisfactory fit. 


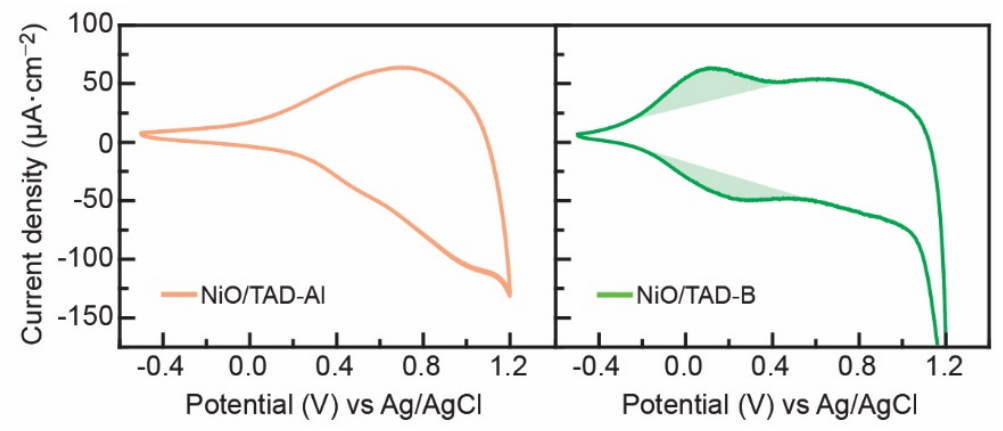

Figure S3. Cyclic voltammetry of $\mathrm{NiO}$ treated with $\mathrm{TAD}$ of $\mathrm{Al}$ (left, orange curve) and treated with TAD of B (right, green curve). The shaded green region denotes the trap-state density remaining in B-treated $\mathrm{NiO}$ films that is not present in the Al-treated $\mathrm{NiO}$ films. 

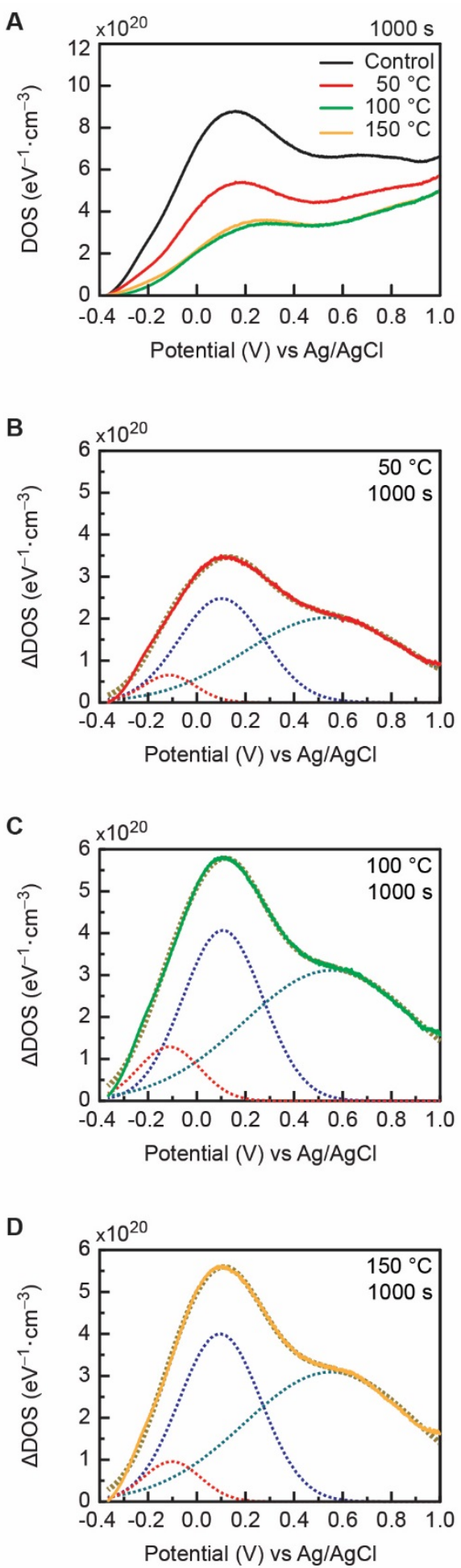

Figure S4. Temperature progression of defect site passivation. (A) Density of states versus $\mathrm{Ag} / \mathrm{AgCl}$ for films of untreated $\mathrm{NiO}$ (black) and $\mathrm{NiO}$ with a $\mathrm{TAD}$ of $\mathrm{B}$ at $50{ }^{\circ} \mathrm{C}$ (red), $100{ }^{\circ} \mathrm{C}$ (green), and $150{ }^{\circ} \mathrm{C}$ (yellow). (B-D) Difference DOS spectra determined by subtracting the treated NiO DOS from the untreated $\mathrm{NiO}$ spectra for 1000 seconds at $50{ }^{\circ} \mathrm{C}$ (panel B and red line), $100{ }^{\circ} \mathrm{C}$ (panel $\mathrm{C}$ and green line), and $150^{\circ} \mathrm{C}$ (panel $\mathrm{D}$ and yellow line). The difference spectra are well fit to the summation of three Gaussian peaks (dashed lines) centered at $-0.11,0.10$, and $0.55 \mathrm{~V}$ vs $\mathrm{Ag} / \mathrm{AgCl}$. 

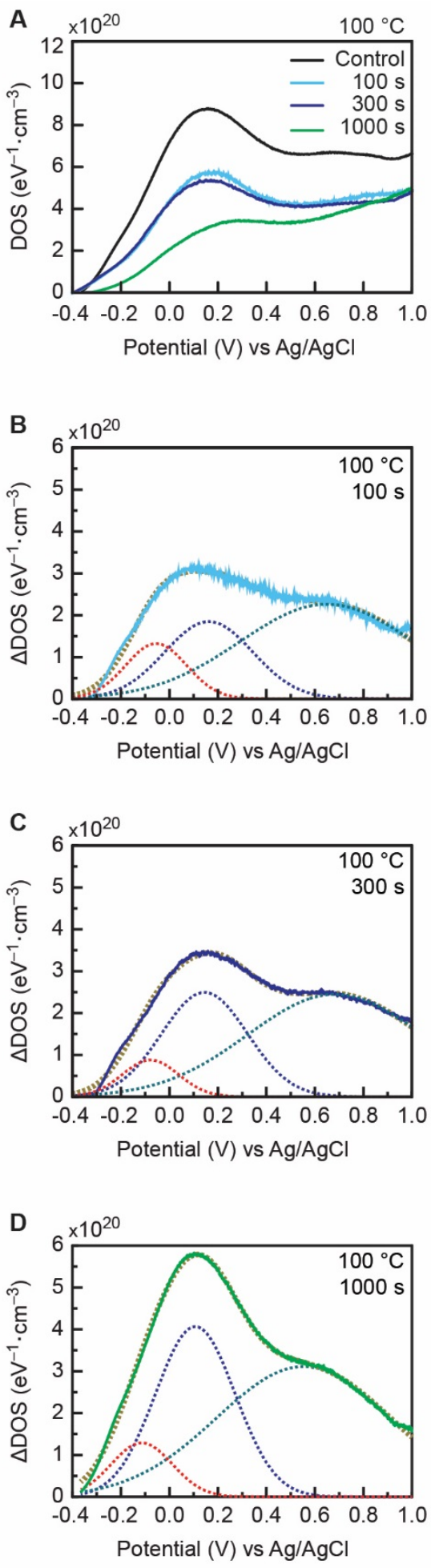

Figure S5. Time progression of defect site passivation at $100^{\circ} \mathrm{C}$. (A) Density of states versus $\mathrm{Ag} / \mathrm{AgCl}$ for films of untreated $\mathrm{NiO}$ (black) and $\mathrm{NiO}$ with a TAD of $\mathrm{B}$ at $100^{\circ} \mathrm{C}$ for $100 \mathrm{~s}$ (light blue), $300 \mathrm{~s}$ (dark blue), and $1000 \mathrm{~s}$ (green). (B-D) Difference DOS spectra determined by subtracting the treated NiO DOS from the untreated $\mathrm{NiO}$ spectra at $100{ }^{\circ} \mathrm{C}$ seconds for $100 \mathrm{~s}$ (panel $\mathrm{B}$ and light blue line), $300 \mathrm{~s}$ (panel C and dark blue line), and $1000 \mathrm{~s}$ (panel D and green line). The difference spectra are well fit to the summation of three Gaussian peaks (dashed lines). 


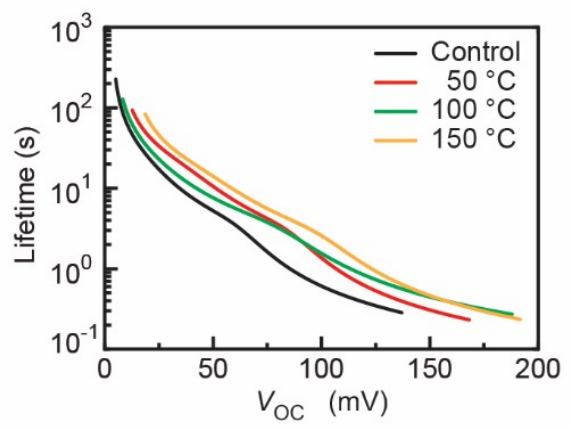

Figure S6. Charge carrier lifetimes by open-circuit voltage decays with a starting illumination of 1-sun for $\mathrm{NiO}$ p-DSSCs (black trace) with a TAD of B for $1000 \mathrm{~s}$ at $50{ }^{\circ} \mathrm{C}$ (red trace), $100{ }^{\circ} \mathrm{C}$ (green trace), and $150{ }^{\circ} \mathrm{C}$ (yellow trace).

A

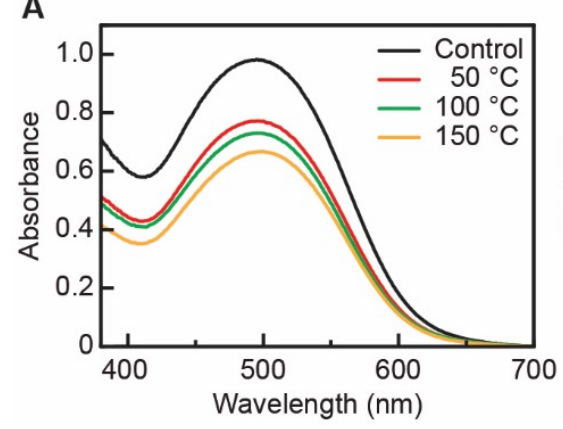

B

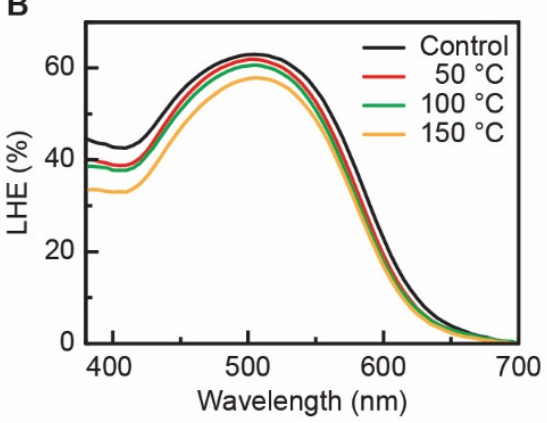

C

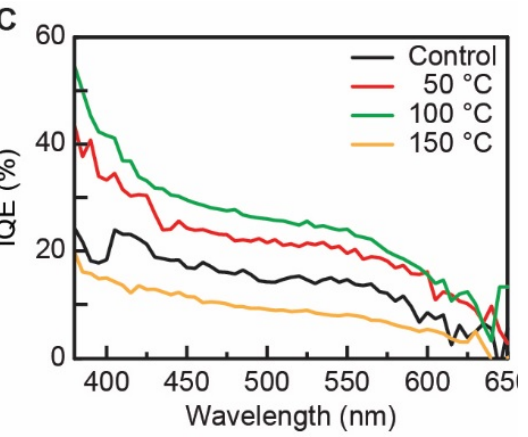

Figure S7. Absorption and quantum efficiency characteristics of dye-loaded electrodes. (A) Absorbance spectra, $\boldsymbol{A}_{\mathrm{P} 1}$, of the P1 chromophore on NiO films. Using the measured film thickness of $\sim 900 \mathrm{~nm}$ and the known extinction coefficient at $\lambda_{\max }$, we derive dye loading values of $20,16,16$, and $13 \mathrm{nmol} \cdot \mathrm{cm}^{-2} \cdot \mu \mathrm{m}^{-1}$ for the untreated, 50, 100, and $150{ }^{\circ} \mathrm{C}$ samples, respectively. (B) Light harvesting efficiency (LHE), and (C) internal quantum efficiency (IQE) for $\mathrm{NiO}$ electrodes sensitized with the $\mathrm{P} 1$ chromophore without treatment (black traces) and with a TAD of B for $1000 \mathrm{~s}$ at $50{ }^{\circ} \mathrm{C}$ (red traces), $100{ }^{\circ} \mathrm{C}$ (green traces), and $150{ }^{\circ} \mathrm{C}$ (yellow traces). Despite the decrease in the dye loading of $\mathrm{P} 1$ with the addition of boron, the optical bleaching of the $\mathrm{NiO}$ films compensates for this drop in light absorption by the chromophore, resulting in nearly equivalent LHEs after TAD treatment. 
Table S1. Estimations of internal quantum efficiency (IQE)

\begin{tabular}{|c|c|c|c|c|c|}
\hline $\begin{array}{c}\text { Deposition } \\
T\left({ }^{\circ} \mathrm{C}\right)\end{array}$ & $\begin{array}{c}J_{\mathrm{SC}}^{\mathrm{a}} \\
\left(\mathrm{mA} \cdot \mathrm{cm}^{-2}\right) \\
\end{array}$ & $\begin{array}{l}J_{\mathrm{SC}}(\mathrm{EQE})^{\mathrm{b}} \\
\left(\mathrm{mA} \cdot \mathrm{cm}^{-2}\right)\end{array}$ & $\begin{array}{l}J_{\mathrm{SC}}(\mathrm{LHE})^{\mathrm{c}} \\
\left(\mathrm{mA} \cdot \mathrm{cm}^{-2}\right) \\
\end{array}$ & $\begin{array}{c}\mathrm{IQE}^{\mathrm{d}} \\
J_{\mathrm{SC}} / J_{\mathrm{SC}}(\mathrm{LHE}) \\
(\%) \\
\end{array}$ & $\begin{array}{c}\mathrm{IQE}^{\mathrm{e}} \\
J_{\mathrm{SC}}(\mathrm{EQE}) / J_{\mathrm{SC}}(\mathrm{LHE}) \\
(\%)\end{array}$ \\
\hline- & $1.2 \pm 0.1$ & 1.07 & 6.8 & $18 \pm 1$ & 15.7 \\
\hline 50 & $1.29 \pm 0.05$ & 1.51 & 6.4 & $20 \pm 1$ & 23.6 \\
\hline 100 & $1.3 \pm 0.2$ & 1.73 & 6.3 & $21 \pm 3$ & 27.5 \\
\hline 150 & $0.51 \pm 0.09$ & 0.56 & 5.8 & $9 \pm 2$ & 6.2 \\
\hline
\end{tabular}

a The average $J_{\mathrm{SC}}$ value measured from devices under 1-sun illumination

${ }^{\mathrm{b}}$ The $J_{\mathrm{SC}}$ value determined from champion devices by integrating the EQE spectra with the AM1.5G solar spectrum

${ }^{\mathrm{c}}$ The maximum theoretical $J_{\mathrm{SC}}$ determined by integrating the LHE spectra with the AM1.5G solar spectrum

d The IQE determined by dividing the $J_{\mathrm{SC}}$ of devices under 1 -sun illumination by the maximum theoretical $J_{\mathrm{SC}}$ determined by integrating the LHE spectra with the AM1.5G solar spectrum

e The IQE determined by dividing the $J_{\mathrm{SC}}$ determined from the EQE spectra by the maximum theoretical $J_{\mathrm{SC}}$ determined by integrating the LHE spectra with the AM1.5G solar spectrum 